\title{
Internal consistency and item-total correlation of patient-reported outcome instruments and hemophilia joint health score v2.I in US adult people with hemophilia: results from the Pain, Functional Impairment, and Quality of life (P-FiQ) study
}

\author{
This article was published in the following Dove Press journal: \\ Patient Preference and Adherence \\ 25 October 2017 \\ Number of times this article has been viewed
}

\section{Michael Wang,' Katharine \\ Batt, ${ }^{2}$ Craig Kessler, ${ }^{3}$ Anne Neff, ${ }^{4}$ Neeraj N lyer, ${ }^{5}$ David L Cooper, ${ }^{5}$ Christine L Kempton ${ }^{6}$}

'Hemophilia and Thrombosis Center, University of Colorado School of Medicine, Aurora, $\mathrm{CO},{ }^{2} \mathrm{Hematology}$ and Oncology, Wake Forest School of Medicine, Winston-Salem, NC, ${ }^{3}$ Department of Medicine and Pathology, Division of Hematology/ Oncology, Georgetown University Hospital, Washington, DC, ${ }^{4} \mathrm{Hematology}$ and Medical Oncology, Cleveland Clinic, Cleveland, $\mathrm{OH}$, ${ }^{5}$ Novo Nordisk Inc., Clinical, Medical, and Regulatory Affairs, Plainsboro, NJ, ${ }^{6}$ Departments of Pediatrics and Hematology and Medical Oncology, Emory University School of Medicine, Atlanta, GA, USA

Correspondence: Michael Wang Hemophilia and Thrombosis Center University of Colorado School of Medicine, Anschutz Medical Campus Center for Cancer and Blood Disorders, Children's Hospital Colorado, I3199 East Montview Blvd., Suite 100, Aurora, CO 80045 , USA

Tel +l 3037240365

Fax +I 3037240078

Email michael.wang@ucdenver.edu
Background: The Pain, Functional Impairment, and Quality of Life study was an observational, cross-sectional assessment of the impact of pain on functional impairment and quality of life in adult people with hemophilia (PWH) of any severity in the USA who experience joint pain and/or bleeding.

Objective: To assess internal consistency (IC) and item-total correlation (ITC) of assessment tools used in the Pain, Functional Impairment, and Quality of Life study.

Methods: Participants completed 5 patient-reported outcome instruments (EQ-5D-5L with visual analog scale, Brief Pain Inventory v2 Short Form [BPI], International Physical Activity Questionnaire [IPAQ], Short Form 36 Health Survey v2 [SF-36v2], and Hemophilia Activities List [HAL]) and underwent an optional physiotherapist-administered musculoskeletal exam (Hemophilia Joint Health Score v2.1) during routine visits. Reliability assessment included IC and ITC of each instrument. Results: A total of 381 adult PWH (median age, 34 years) were enrolled. Participants were predominantly white/non-Hispanic (69.2\%); 75\% had congenital hemophilia A, and $70.5 \%$ had severe hemophilia. A total of 310 subjects reported bleeding within the past 6 months (mean [SD] number of bleeds, 7.1 [13.00]). IC was generally high across the instruments employed (Cronbach's alpha 0.79-0.98) with the exception of HAL use of transportation (0.58) and IPAQ total physical activity (0.51). ITC was high (Pearson's product-moment correlation coefficient $>0.20$ ) for all items except the "vigorous intensity activities" item of IPAQ, which was applicable to less than one-third of participants. The ITCs were generally highest in domains/scores that measured the functional consequences of hemophilic arthropathy on mobility and pain.

Conclusion: The demonstrated reliability (IC/ITC) of the patient-reported outcome instruments and Hemophilia Joint Health Score v2.1 support a role for these instruments in evaluating adult PWH in US clinical and research settings.

Keywords: hemophilia, pain, functional impairment, quality of life, patient-reported outcome, joint health

\section{Introduction}

The Pain, Functional Impairment, and Quality of Life (P-FiQ) study was an observational, cross-sectional assessment of the impact of pain on functional impairment 
and health-related quality of life (HRQoL) in adult people with hemophilia (PWH) of any severity in the USA who experience joint pain or bleeding. The study was designed to assess HRQoL parameters (primary objective) as well as reliability and validity of the general and disease-specific patient-reported outcome (PRO) instruments and physical therapist-administered joint assessment tool used (secondary objective). Overall, P-FiQ demonstrated a high prevalence of pain and functional impairment in the study population, with approximately three-fourths (76.1\%) of participants reporting pain and/or discomfort at the time of assessment, and 61.4\% reporting impaired mobility. ${ }^{1-3}$ An overall negative impact on HRQoL was observed, particularly with respect to physical domains, and was generally greatest in domains related to lower vs upper extremity joints.

The P-FiQ study used 5 generic and disease-specific PRO instruments (EQ-5D-5L, Brief Pain Inventory v2 Short Form [BPI], International Physical Activity Questionnaire [IPAQ], Short Form 36 Health Survey v2 [SF-36v2], and Hemophilia Activities List [HAL]) and one clinicianadministered joint evaluation tool (Hemophilia Joint Health Score v2.1 [HJHS]) to assess pain, functional impairment, and quality of life in the enrolled population. ${ }^{2}$ Of the PRO instruments used, only 3 have previously been employed in clinical studies conducted in PWH in the USA (SF-36, 4,5 EQ-5D, ${ }^{6,7}$ and $\mathrm{HAL}^{8}$ ), and none have been validated in English-speaking PWH. Of note, the 2 previous studies using the EQ-5D employed the 3-level response version (EQ-5D-3L), and P-FiQ was the first US hemophilia study in which the 5-level response version (EQ-5D-5L) ${ }^{9}$ was used. P-FiQ is also one of few reports using the physical therapist-administered HJHS in adult PWH, likely because the HJHS was not designed for this purpose (it was developed to detect early signs of joint damage in children with hemophilia ${ }^{10,11}$, and it has not yet been assessed for reliability or validity in adults.

The extent and impact of pain on functioning and HRQoL are generally accepted to be important considerations in $\mathrm{PWH}$, as recurrent joint bleeds may result in progressive hemophilic arthropathy; however, PWH are rarely assessed in the clinical setting through use of PRO instruments or in any consistent fashion at hemophilia treatment centers. Surveys conducted in both the USA ${ }^{12}$ and Europe ${ }^{13}$ have shown that pain assessment and management tools are generally underutilized by hemophilia treatment centers. In the USA, only $15 \%$ of the 98 centers surveyed indicated that pain management was formally a part of their comprehensive care approach. ${ }^{12}$ Likewise, in Europe, only 8 (36\%) of 22 centers surveyed reported the use of any formal pain assessment scales, and only 2 reported using the services of a pain specialist, despite the high prevalence of arthropathy $(67 \%)$ and chronic pain (38\%) observed among the adults they treated. ${ }^{13}$ This apparent omission is likely at least partially attributable to the lack of demonstrated applicability of available assessment tools.

This report describes the internal consistency (IC; the extent to which items within an instrument measure the same concept) and item-total correlation (ITC; the contribution of each item to instrument consistency as determined by the ability to discriminate between high- and low-scoring individuals) of the 5 PRO instruments and HJHS in adult PWH in the P-FiQ study. Test-retest reliability was also evaluated in a subset of the initial patients enrolled in the study, and validity (construct validity and known-group validity) was evaluated as a secondary objective of the study; results of these analyses are presented separately within this thematic series..$^{14,15}$

\section{Methods}

\section{Study design}

The P-FiQ study (NCT01988532) was an observational, cross-sectional assessment of adult PWH designed to assess the impact of pain on functional impairment and HRQoL. Male PWH either with or without inhibitors to coagulation factors VIII or IX, aged 18 years or older, and with a history of joint pain or bleeding completed 5 PRO instruments and underwent a musculoskeletal exam during a routine comprehensive care visit, while in a non-bleeding state. Subjects in a retest cohort completed the PRO instruments again at the end of their visit (3-4 hours later). The study enrolled participants at 15 US sites between October 2013 and October 2014, and informed consent was obtained from all participants prior to engagement in study-related activities. All surveys were conducted in English. The names of all approving institutional review boards are listed in the Supplementary material.

\section{Patient-reported outcome and HJHS scales}

The 5-level EQ-5D (EQ-5D-5L) ${ }^{9}$ was used to assess current ("today") health status. Subjects rated their current health state on a 100-point (20-cm) visual analog scale with anchors of "worst imaginable" and "best imaginable." Subjects also rated health status across 5 domains (mobility, self-care, usual activities, pain/discomfort, and anxiety/depression) using 5 response levels (none, slight, moderate, severe, or 
extreme problems). Index summary scores were calculated using the EuroQoL index value calculator. ${ }^{16}$

The $\mathrm{BPI}^{17}$ was used to evaluate pain severity and interference. Subjects rated pain severity (current, worst, least, and average) and pain interference (effects on general activity, mood, walking ability, normal work, relations with other people, sleep, and enjoyment of life) during the past 7 days on scale of 1 ("no pain" or "does not interfere") to 10 ("pain as bad as you can imagine" or "completely interferes").

The IPAQ short form ${ }^{18}$ was used to measure the level of physical activity over the previous week. Participants provided the time (duration and frequency) spent walking as well as engaging in vigorous-intensity and moderate-intensity activities. A weighted estimate of total activity per week (metabolic equivalents of task [MET] min/wk) was calculated using MET energy expenditure estimates assigned to each category of activity (walking, $3.3 \mathrm{METs} / \mathrm{min}$; moderate activities, 4.0 METs/min; vigorous activities, 8.0 METs/min). Participants reporting no physical activity in the prior week were excluded from MET analyses.

The 36-question SF-36v2 $2^{19}$ was used to assess health status across 8 domains (physical functioning, role physical, bodily pain, general health, vitality, social functioning, role emotional, and mental health) over the preceding 4 weeks. Responses were recorded using a 100-point scale on which higher scores were indicative of better health status. Psychometrically based physical and mental health summary scores were also derived.

The HAL ${ }^{20,21}$ was used to assess function across 7 domains (lying/sitting/kneeling/standing, functions of the legs, functions of the arms, use of transportation, self-care, household tasks, and leisure activities and sports) over the preceding month. Responses were recorded using a 0 - to 100 point scale, with higher scores indicating better functional status. Additionally, 3 component scores (upper extremity activities, basic lower extremity activities, and complex lower extremity activities) and an overall score were calculated from domain scores.

The HJHS v2. $1^{11}$ was used to assess joint impairment and gait. Investigators (or their designees) rated multiple items (swelling, duration of swelling, muscle atrophy, crepitus on motion, flexion loss, extension loss, joint pain, and strength) for left and right elbow, knee, and ankle joints, and calculated a total score for each of 3 domains (elbows, knees, and ankles). Potential scores ranged from 0 to 40 for each domain, with lower scores indicative of better function. Additionally, investigators assigned a global gait score (range, $0-4$ ) based on the assessment of skills relating to walking, climbing stairs, running, and hopping on 1 leg. A total HJHS score was obtained by summing the totals for each joint and global gait (potential total HJHS score range, 0-124).

\section{Statistical analysis}

IC was evaluated by Cronbach's alpha ( $\alpha$ ), a widely used measure of variability. All domains and global scores were assessed using this approach, and Cronbach's $\alpha$ values $>0.70$ were considered satisfactory. ${ }^{22}$

ITC was evaluated by Pearson's product-moment correlation coefficient $(r)$. The correlation between each individual item and the domain and/or global scores omitting the item was assessed; correlation values $>0.20$ were considered satisfactory. ${ }^{23}$ Alpha indicates the IC of the remaining items if the selected items were deleted from the total score.

\section{Results \\ Participants}

A total of $381 \mathrm{PWH}$ were enrolled in the study, with a median age of 34 years (range, 18-86 years). Subjects were predominantly white and non-Hispanic (69.2\%), well educated $(60.7 \%$ had a college, graduate, or postgraduate level of education), and employed (77.2\% worked full or part time or were selfemployed). Approximately three-fourths (75\%) of subjects had congenital hemophilia A; most had severe hemophilia $(70.5 \%)$, and a minority $(8.7 \%)$ had inhibitors. A total of 310 subjects reported bleeding within the past 6 months; the mean (SD) number of bleeds in this subgroup was 7.1 (13.0). Nearly half were currently receiving routine infusions to prevent bleeding ( $43.5 \%)$; others were receiving on-demand (37.7\%) or mostly on-demand (18.7\%) treatment of bleeding. Approximately one-third (31.5\%) reported spending at least half of their life on prophylaxis. A subset of subjects (240 [63\%]) underwent the optional HJHS assessment.

\section{Internal consistency}

Cronbach's $\alpha$ values (Table 1) were above the threshold of 0.70 and ranged from 0.79 to 0.98 across the domains of the PRO scales and the HJHS, with the exception of HAL use of transportation $(\alpha=0.58)$ and IPAQ total physical activity $(\alpha=0.51)$. Of note, 2 of the 3 items within the HAL use of transportation domain were indicated as not applicable to substantial proportions of respondents (using public transportation, $40.7 \%$; riding a bicycle, $28.6 \%$ ). Analysis of IPAQ total physical activity was limited to the 166 participants who reported some physical activity in the prior week (43.6\%); an additional $45.4 \%$ reported $<10$ minutes of activity per week, and $11.0 \%$ had missing data. 
Table I Internal consistency of patient-reported outcome and HJHS scores

\begin{tabular}{|c|c|c|}
\hline Item & $\mathbf{n}$ & $\begin{array}{l}\text { Cronbach's } \\
\text { alpha }\end{array}$ \\
\hline \multicolumn{3}{|l|}{ EQ-5D-5L } \\
\hline Index & 375 & 0.81 \\
\hline \multicolumn{3}{|l|}{ BPI } \\
\hline Pain severity & 372 & 0.92 \\
\hline Pain interference & 375 & 0.96 \\
\hline \multicolumn{3}{|l|}{ IPAQ } \\
\hline Total physical activity ${ }^{a}$ & 208 & $0.5 I^{*}$ \\
\hline \multicolumn{3}{|l|}{ SF-36v2 } \\
\hline Physical functioning & 376 & 0.94 \\
\hline Role physical & 374 & 0.96 \\
\hline Bodily pain & 379 & 0.87 \\
\hline General health & 376 & 0.82 \\
\hline Vitality & 379 & 0.79 \\
\hline Social functioning & 377 & 0.86 \\
\hline Role emotional & 377 & 0.96 \\
\hline Mental health & 375 & 0.86 \\
\hline Physical health summary & 361 & 0.96 \\
\hline Mental health summary & 361 & 0.96 \\
\hline \multicolumn{3}{|l|}{ HAL } \\
\hline Lying/sitting/kneeling/standing & 368 & 0.94 \\
\hline Functions of the legs & 372 & 0.96 \\
\hline Functions of the arms & 378 & 0.89 \\
\hline Use of transportation & 377 & $0.58 *$ \\
\hline Self-care & 379 & 0.90 \\
\hline Household tasks & 378 & 0.92 \\
\hline Leisure activities and sports & 377 & 0.89 \\
\hline Upper extremity activities & 376 & 0.92 \\
\hline Basic lower extremity activities & 375 & 0.96 \\
\hline Complex lower extremity activities & 370 & 0.94 \\
\hline Total score & 348 & 0.98 \\
\hline \multicolumn{3}{|l|}{ HJHS } \\
\hline Total score & 228 & 0.97 \\
\hline
\end{tabular}

Notes: ${ }^{2}$ Excluding participants with no reported physical activity. ${ }^{*}$ Cronbach's alpha $\leq 0.70$.

Abbreviations: BPI, Brief Pain Inventory v2 Short Form; HAL, Hemophilia Activities List; HJHS, Hemophilia Joint Health Score v2.I; IPAQ, International Physical Activity Questionnaire; SF-36v2, Short Form 36 Health Survey v2.

\section{Item-total correlation}

\section{EuroQoL 5 Dimensions 5 Levels}

All EQ-5D-5L items exhibited satisfactory correlation with the index score (Pearson's $r>0.2$ ) and ranged from 0.39 to 0.73 (Table 2). Mobility, usual activities, and pain/discomfort showed the highest correlations with index scores $(\mathrm{r}=0.70-0.73)$. Self-care and anxiety/depression were less correlated with index scores ( $r=0.53$ and 0.39 , respectively), and IC was slightly higher when these items were deleted from the total score $(\alpha=0.80$ and 0.83 , respectively, compared with $0.73-0.74)$. Of note, self-care and anxiety/depression problems were reported by a minority of subjects $(18.9 \%$ and $43.4 \%$, respectively).
Table 2 Item-total correlation: EQ-5D-5L, BPI, and IPAQ

\begin{tabular}{|c|c|c|}
\hline Item & Pearson's $r$ & Alpha $^{a}$ \\
\hline \multicolumn{3}{|l|}{ EQ-5D-5L index } \\
\hline Mobility & 0.70 & 0.74 \\
\hline Self-care & 0.53 & 0.80 \\
\hline Usual activities & 0.71 & 0.73 \\
\hline Pain/discomfort & 0.73 & 0.73 \\
\hline Anxiety/depression & 0.39 & 0.83 \\
\hline \multicolumn{3}{|l|}{ BPI pain severity } \\
\hline Worst pain & 0.79 & 0.92 \\
\hline Least pain & 0.79 & 0.91 \\
\hline Average pain & 0.88 & 0.88 \\
\hline Current pain & 0.85 & 0.89 \\
\hline \multicolumn{3}{|l|}{$\mathrm{BPI}$ pain interference } \\
\hline General activity & 0.90 & 0.95 \\
\hline Mood & 0.88 & 0.95 \\
\hline Walking ability & 0.79 & 0.96 \\
\hline Normal work & 0.87 & 0.95 \\
\hline Relations with other people & 0.82 & 0.95 \\
\hline Sleep & 0.82 & 0.95 \\
\hline Enjoyment of life & 0.88 & 0.95 \\
\hline \multicolumn{3}{|c|}{ IPAQ total physical activity } \\
\hline Walking & 0.50 & 0.26 \\
\hline Moderate intensity activities & 0.67 & 0.13 \\
\hline Vigorous intensity activities & $0.12 *$ & 0.64 \\
\hline $\begin{array}{l}\text { Notes: andicates internal consis } \\
\text { deleted from the total score. } \\
\text { activity. }{ }^{*} \leq 0.20 \text {. } \\
\text { Abbreviations: BPI, Brief Pain } \\
\text { Physical Activity Questionnaire; } r \\
\text { total score. }\end{array}$ & $\begin{array}{l}\text { maining items if th } \\
\text { articipants with } \\
\text { v2 Short Form; } \\
\text { product-moment }\end{array}$ & $\begin{array}{l}\text { item were } \\
\text { d physical } \\
\text { ernational } \\
\text { with the }\end{array}$ \\
\hline
\end{tabular}

\section{Brief Pain Inventory v2 Short Form}

All items within BPI pain severity had high ITC, ranging from 0.79 (worst pain and least pain) to 0.88 (average pain) (Table 2). BPI pain interference domains also showed high ITCs, ranging from 0.79 (walking ability) to 0.90 (general activity).

\section{International Physical Activity Questionnaire}

Despite the limited number of subjects reporting any activity in the prior week, both walking and moderate intensity activities had satisfactory correlation with the total physical activity score ( $r=0.50$ and 0.67 , respectively; Table 2 ). Vigorous intensity activities exhibited low correlation with total physical activity $(\mathrm{r}=0.12)$; however, it is notable that only 55 participants $(33.1 \%$ of those who engaged in any physical activity) reported engaging in any vigorous activities during the week prior to the survey.

\section{Short Form 36 Health Survey v2}

All items within the SF-36v2 exhibited satisfactory correlation with their respective domain scores ( $\mathrm{r}=0.42-0.93$; Table 3 ). 
Table 3 Item-total correlation: SF-36v2

\begin{tabular}{|c|c|c|}
\hline Item & Pearson's $r$ & Alpha $^{a}$ \\
\hline \multicolumn{3}{|l|}{ Physical functioning } \\
\hline Vigorous activity & 0.68 & 0.94 \\
\hline Moderate activity & 0.80 & 0.93 \\
\hline Lifting or carrying groceries & 0.75 & 0.94 \\
\hline Climbing several flights of stairs & 0.83 & 0.93 \\
\hline Climbing one flight of stairs & 0.80 & 0.93 \\
\hline Bending, kneeling, or stooping & 0.73 & 0.94 \\
\hline Walking more than a mile & 0.84 & 0.93 \\
\hline Walking several hundred yards & 0.86 & 0.93 \\
\hline Walking one hundred yards & 0.78 & 0.93 \\
\hline Bathing or dressing & 0.50 & 0.94 \\
\hline \multicolumn{3}{|l|}{ Role physical } \\
\hline $\begin{array}{l}\text { Cut down amount of work time due } \\
\text { to physical health }\end{array}$ & 0.89 & 0.95 \\
\hline $\begin{array}{l}\text { Accomplished less than you would like, } \\
\text { due to physical health }\end{array}$ & 0.90 & 0.94 \\
\hline $\begin{array}{l}\text { Limited in the kind of work, due } \\
\text { to physical health }\end{array}$ & 0.89 & 0.95 \\
\hline $\begin{array}{l}\text { Difficulty performing work, due } \\
\text { to physical health }\end{array}$ & 0.90 & 0.94 \\
\hline \multicolumn{3}{|l|}{ Bodily pain } \\
\hline Bodily pain during past 4 weeks & 0.77 & NA \\
\hline Pain interference, normal work & 0.77 & NA \\
\hline \multicolumn{3}{|l|}{ General health } \\
\hline General health status & 0.70 & 0.76 \\
\hline Get sick a little easier than others & 0.69 & 0.76 \\
\hline Healthy as others & 0.76 & 0.74 \\
\hline Expect health will get worse & 0.42 & 0.84 \\
\hline Health is excellent & 0.52 & 0.81 \\
\hline \multicolumn{3}{|l|}{ Vitality } \\
\hline Feel full of life & 0.56 & 0.76 \\
\hline Have a lot of energy & 0.62 & 0.73 \\
\hline Feel worn out & 0.63 & 0.73 \\
\hline Feel tired & 0.61 & 0.74 \\
\hline \multicolumn{3}{|l|}{ Social functioning } \\
\hline $\begin{array}{l}\text { Severity of interference with normal } \\
\text { social activity }\end{array}$ & 0.76 & NA \\
\hline Time of interference with social activities & 0.76 & NA \\
\hline \multicolumn{3}{|l|}{ Role emotional } \\
\hline $\begin{array}{l}\text { Cut down amount of work time, due } \\
\text { to emotional health }\end{array}$ & 0.93 & 0.92 \\
\hline $\begin{array}{l}\text { Accomplished less than you would like, } \\
\text { due to emotional health }\end{array}$ & 0.92 & 0.93 \\
\hline $\begin{array}{l}\text { Worked less carefully than usual, due } \\
\text { to emotional health }\end{array}$ & 0.87 & 0.96 \\
\hline \multicolumn{3}{|l|}{ Mental health } \\
\hline Feel calm and peaceful & 0.65 & 0.83 \\
\hline Feel happy & 0.62 & 0.84 \\
\hline Feel very nervous & 0.62 & 0.84 \\
\hline Feel down in the dumps & 0.72 & 0.82 \\
\hline Feel downhearted and depressed & 0.76 & 0.80 \\
\hline
\end{tabular}

Note: andicates internal consistency of remaining items if the elected item were deleted from the total score.

Abbreviations: NA, not assessable; $r$, Pearson's product-moment correlation with the total score; SF-36v2, Short Form 36 Health Survey v2.
In general, items in the role physical and role emotional domains had relatively high correlations ( $\mathrm{r}=0.87-0.93$ ), and items in the vitality domain had lower correlations $(\mathrm{r}=0.56-0.63)$. Overall, items with the lowest correlations were "expect health will get worse" and "health is excellent" with the total general health score ( $\mathrm{r}=0.42$ and 0.52 , respectively) and "bathing or dressing" with the total physical functioning score $(\mathrm{r}=0.50)$. Deletion of "expect health will get worse" and "health is excellent" from the total general health score resulted in notable improvements in IC $(\alpha=0.84$ and 0.81 , respectively, compared with $0.74-0.76$ ). The relatively low ITC of "bathing or dressing" compared with other items in the physical functioning domain suggests that mobility-related items, rather than self-care items, drive the physical functioning domain score.

\section{Hemophilia Activities List}

All items on the HAL had satisfactory correlation with total domain scores ( $\mathrm{r}=0.34-0.92$; Table 4$)$. In general, the lowest correlations were observed in the domain use of transportation ( $r=0.34-0.49$ ); however, 2 of these items showed high numbers of "not applicable" responses (using public transportation, $40.7 \%$; riding a bicycle $28.6 \%$ ). Riding a bicycle also exhibited a low correlation with the domain score complex lower extremity activities $(\mathrm{r}=0.44)$.

\section{Hemophilia Joint Health Score v2.I}

All items on the HJHS had satisfactory correlation with their respective joint total scores ( $\mathrm{r}=0.34-0.83$; Table 5$)$. Within each HJHS domain, ITC varied across component scores. For example, within the ankle domain, correlation was highest for crepitus (left, $r=0.74$; right, $r=0.73$ ) and lowest for strength (left, $r=0.54$; right, $r=0.49$ ). The lowest ITC was for global gait $(\mathrm{r}=0.34)$.

\section{Discussion}

The current analysis of data from the P-FiQ study supports the PRO instruments and HJHS as appropriate for use in clinical and research settings in the USA. Overall, the tools used in P-FiQ exhibited sufficient IC, with the majority of Cronbach's $\alpha$ scores falling between 0.79 and 0.98 . These scores represent high levels of domain/global score correlation. The 2 notable exceptions (the transportation domain of HAL and the total physical activity domain of IPAQ) may reflect the small numbers of participants to which these activities applied. ITC was established for all instruments except for the "vigorous intensity activities" item of the 
Table 4 Item-total correlation: Hemophilia Activities List

\begin{tabular}{|c|c|c|}
\hline Item & Pearson's $r$ & Alpha $^{a}$ \\
\hline \multicolumn{3}{|l|}{ Lying/sitting/kneeling/standing } \\
\hline Sitting down & 0.68 & 0.94 \\
\hline Rising from a chair with armrests & 0.80 & 0.93 \\
\hline Rising from a chair without armrests & 0.83 & 0.93 \\
\hline Kneeling/squatting & 0.88 & 0.93 \\
\hline Bending forward & 0.72 & 0.94 \\
\hline Kneeling long time & 0.86 & 0.93 \\
\hline Squatting long time & 0.86 & 0.93 \\
\hline Standing long time & 0.79 & 0.93 \\
\hline \multicolumn{3}{|l|}{ Functions of the legs } \\
\hline Walking long distances & 0.81 & 0.96 \\
\hline Walking on a soft surface & 0.89 & 0.96 \\
\hline Walking on an uneven surface & 0.87 & 0.96 \\
\hline Strolling & 0.89 & 0.96 \\
\hline Climbing up the stairs & 0.84 & 0.96 \\
\hline Climbing down the stairs & 0.89 & 0.96 \\
\hline Running & 0.88 & 0.96 \\
\hline Jumping & 0.82 & 0.96 \\
\hline \multicolumn{3}{|l|}{ Functions of the arms } \\
\hline Lifting heavy objects & 0.84 & 0.82 \\
\hline Carrying heavy objects & 0.87 & 0.81 \\
\hline Fine hand movements & 0.65 & 0.90 \\
\hline Reaching above your head & 0.72 & 0.87 \\
\hline \multicolumn{3}{|l|}{ Use of transportation } \\
\hline Riding a bicycle & 0.49 & 0.39 \\
\hline Getting in and out of car & 0.45 & 0.44 \\
\hline Using public transportation & 0.34 & 0.57 \\
\hline \multicolumn{3}{|l|}{ Self-care } \\
\hline Drying your whole body & 0.82 & 0.87 \\
\hline Putting on a shirt, sweater, etc. & 0.83 & 0.87 \\
\hline Putting on socks and shoes & 0.78 & 0.88 \\
\hline Putting on a tie & 0.74 & 0.89 \\
\hline Going to the toilet & 0.67 & 0.90 \\
\hline \multicolumn{3}{|l|}{ Household tasks } \\
\hline Going out shopping & 0.72 & 0.91 \\
\hline Washing the dishes & 0.83 & 0.90 \\
\hline Cleaning the house & 0.89 & 0.89 \\
\hline Other household tasks & 0.85 & 0.90 \\
\hline Doing odd jobs & 0.86 & 0.89 \\
\hline Gardening & 0.60 & 0.94 \\
\hline \multicolumn{3}{|l|}{ Leisure activities and sports } \\
\hline Playing games (outdoors) & 0.69 & 0.87 \\
\hline Sports & 0.72 & 0.88 \\
\hline Going out (theater/museum/bar) & 0.76 & 0.87 \\
\hline Hobbies & 0.64 & 0.88 \\
\hline Dancing & 0.67 & 0.88 \\
\hline Going on a holiday (active) & 0.76 & 0.87 \\
\hline Going on a holiday (passive/beach/hotel) & 0.72 & 0.87 \\
\hline \multicolumn{3}{|l|}{ Upper extremity activities } \\
\hline Lifting heavy objects & 0.73 & 0.91 \\
\hline Carrying heavy objects & 0.75 & 0.91 \\
\hline Fine hand movements & 0.74 & 0.91 \\
\hline Reaching above your head & 0.78 & 0.90 \\
\hline Drying your whole body & 0.75 & 0.91 \\
\hline Putting on a shirt, sweater, etc. & 0.78 & 0.91 \\
\hline Putting on socks and shoes & 0.73 & 0.91 \\
\hline Putting on a tie & 0.72 & 0.91 \\
\hline Going to the toilet & 0.62 & 0.92 \\
\hline
\end{tabular}

Table 4 (Continued)

\begin{tabular}{lll}
\hline Item & Pearson's $\boldsymbol{r}$ & Alpha $^{\mathbf{a}}$ \\
\hline Basic lower extremity activities & & \\
Standing long time & 0.77 & 0.96 \\
Walking short distances & 0.86 & 0.95 \\
Walking long distances & 0.92 & 0.94 \\
Walking on a soft surface & 0.88 & 0.95 \\
Walking on an uneven surface & 0.89 & 0.94 \\
Strolling & 0.87 & 0.95 \\
Complex lower extremity activities & & \\
Rising from a chair without armrests & 0.75 & 0.94 \\
Kneeling/squatting & 0.88 & 0.93 \\
Kneeling long time & 0.85 & 0.93 \\
Squatting long time & 0.86 & 0.93 \\
Climbing up the stairs & 0.84 & 0.94 \\
Climbing down the stairs & 0.84 & 0.94 \\
Running & 0.84 & 0.93 \\
Jumping & 0.86 & 0.93 \\
Riding a bicycle & 0.44 & 0.96 \\
\hline Note:
\end{tabular}

Note: andicates internal consistency of remaining items if the elected item were deleted from the total score.

Abbreviation: $r$, Pearson's product-moment correlation with the total score.

IPAQ, an item that was applicable to less than one-third of the surveyed population. Across the remaining scales, ITCs were generally highest in domains/scores that measured the functional consequences of hemophilic arthropathy on mobility and pain.

A number of factors may have influenced these findings. A large proportion of PWH either cannot (due to hemophilic arthropathy) or chose not (related or unrelated to hemophilia) to participate in physical activity. ${ }^{24}$ In the current study, $~ 45 \%$ of the adult PWH surveyed reported $<10$ minutes of physical activity over the past week. Among those who did report physical activity, moderate and vigorous activities were uncommon ( $\sim 33 \%$ of those with any physical activity reported participating in each ${ }^{2}$ ). Low levels of participation in physical activity therefore limited the number of responses to questions related to specific activities. This limitation was most apparent on the IPAQ, where the total physical activity score had poor interrelatedness $(\alpha=0.51)$, and ITC for vigorous intensity activity was below the acceptable threshold of $\mathrm{r}=0.20$. The clinical applicability of the IPAQ in PWH in the USA may, therefore, be limited to identifying changes in activity in PWH who are active, and its relevance in PWH who lead more sedentary lifestyles remains uncertain.

Local variability in the relevance of specific PRO items may also have influenced our findings. For example, the HAL items "riding a bicycle" and "using public transportation" were not universally relevant; $28.6 \%$ and $40.7 \%$ of participants, respectively, reported that these items did not apply to them. Low applicability of these items may not be surprising considering the geography of the USA, where bicycling and 
Table 5 Item-total correlation: Hemophilia Joint Health Score

\begin{tabular}{|c|c|c|c|c|c|c|c|c|}
\hline \multirow[t]{2}{*}{ Item } & \multicolumn{2}{|c|}{ Elbow $(n=232)$} & \multicolumn{2}{|c|}{ Knee $(n=23 I)$} & \multicolumn{2}{|c|}{ Ankle $(n=232)$} & \multicolumn{2}{|c|}{ Total $(n=228)$} \\
\hline & Pearson's $r$ & Alpha $^{a}$ & Pearson's $r$ & Alpha $^{a}$ & Pearson's $r$ & Alpha $^{a}$ & Pearson's $r$ & Alpha $^{a}$ \\
\hline Swelling, left & 0.48 & 0.89 & 0.73 & 0.95 & 0.67 & 0.91 & 0.54 & 0.97 \\
\hline Swelling, right & 0.42 & 0.90 & 0.76 & 0.94 & 0.62 & 0.91 & 0.59 & 0.97 \\
\hline Duration (swelling), left & 0.57 & 0.89 & 0.75 & 0.94 & 0.55 & 0.91 & 0.56 & 0.97 \\
\hline Duration (swelling), right & 0.51 & 0.89 & 0.71 & 0.95 & 0.59 & 0.91 & 0.59 & 0.97 \\
\hline Atrophy, left & 0.70 & 0.89 & 0.81 & 0.94 & 0.67 & 0.91 & 0.68 & 0.97 \\
\hline Atrophy, right & 0.62 & 0.89 & 0.83 & 0.94 & 0.64 & 0.91 & 0.70 & 0.97 \\
\hline Crepitus, left & 0.69 & 0.89 & 0.77 & 0.94 & 0.74 & 0.90 & 0.66 & 0.97 \\
\hline Crepitus, right & 0.61 & 0.89 & 0.76 & 0.94 & 0.73 & 0.90 & 0.68 & 0.97 \\
\hline Flexion loss, left & 0.71 & 0.88 & 0.74 & 0.94 & 0.70 & 0.90 & 0.66 & 0.97 \\
\hline Flexion loss, right & 0.67 & 0.89 & 0.77 & 0.94 & 0.68 & 0.90 & 0.70 & 0.96 \\
\hline Extension loss, left & $0.7 \mathrm{I}$ & 0.88 & 0.74 & 0.94 & 0.69 & 0.90 & 0.67 & 0.97 \\
\hline Extension loss, right & 0.67 & 0.89 & 0.75 & 0.94 & 0.67 & 0.91 & 0.69 & 0.96 \\
\hline Joint pain, left & 0.51 & 0.89 & 0.74 & 0.95 & 0.57 & 0.91 & 0.54 & 0.97 \\
\hline Joint pain, right & 0.38 & 0.90 & 0.76 & 0.94 & 0.56 & 0.91 & 0.55 & 0.97 \\
\hline Strength, left & 0.50 & 0.90 & 0.60 & 0.95 & 0.54 & 0.91 & 0.55 & 0.97 \\
\hline Strength, right & 0.50 & 0.90 & 0.55 & 0.95 & 0.49 & 0.92 & 0.54 & 0.97 \\
\hline Global gait & - & - & - & - & - & - & 0.34 & 0.97 \\
\hline
\end{tabular}

Note: andicates internal consistency of remaining items if the elected item were deleted from the total score.

Abbreviation: $r$, Pearson's product-moment correlation with the total score.

public transportation are not always feasible or accessible. Interestingly, the IC of the transportation domain of the HAL in the initial validation study conducted in the Netherlands was also the lowest of all the HAL domains tested $(\alpha=0.64$ vs $0.84-0.96) .{ }^{21}$ The investigators attributed the lower IC in that study to both the limited number of items in the domain (3) as well as the diversity of those items (riding a bicycle, getting in and out of a car, and using public transportation). Of note, in some cases, investigators have omitted certain items deemed to be of limited relevance; for example, a recent validation study using the HAL in PWH in Colombia omitted the transportation domain due to a perceived lack of relevance within the study population. ${ }^{25}$ Overall, the HAL demonstrated satisfactory reliability in the P-FiQ study, and despite this limitation may be useful for evaluating adult PWH in the USA.

Certain aspects of the design of the P-FiQ study may also have influenced our results. The 5 PRO instruments used comprised a substantial number of questions $(>100)$, thus the potential for respondent fatigue must be considered. However, test-retest reliability was acceptable in a subpopulation of $164 \mathrm{PWH},{ }^{15}$ and the assessment of reliability described in this report used the first responses of the entire $381 \mathrm{PWH}$ study population, which may be expected to more accurately reflect participant perception. Additionally, participants were required to be able to complete the scales in English; our findings may not, therefore, be generalizable to Hispanic PWH in the USA $(\sim 11 \%-14 \%$ of people with hemophilia $A$ or $\mathrm{B}^{26}$ ), some of whom may prefer to complete scales in Spanish or respond differently. Furthermore, because the
P-FiQ patient population was selected for a history of joint pain or bleeding, these results cannot be assumed to apply to individuals with less significant joint damage.

\section{Conclusion}

Most of the domains of the 5 PRO instruments and HJHS used in the P-FiQ study demonstrated high IC, with the exception of the HAL use of transportation domain and the IPAQ total physical activity score. ITC was established for all instruments except the "vigorous intensity activities" item of the IPAQ. The demonstrated reliability (IC and ITC) of these instruments support their potential role in evaluating adult PWH within the clinical setting in the USA.

\section{Acknowledgments}

The P-FiQ study was managed by Quintiles Real World and Late Phase, Boston, Massachusetts, and Rockville, Maryland, with statistical analyses provided by Jennifer James, Senior Biostatistician, and was supported financially by Novo Nordisk Inc. Writing assistance was provided by Anna $\mathrm{Abt}, \mathrm{PhD}$, of ETHOS Health Communications, Yardley, Pennsylvania, and was supported financially by Novo Nordisk Inc., Plainsboro, New Jersey, in compliance with international Good Publication Practice guidelines. The abstract of this paper was presented at the 62nd Annual SSC Meeting of the ISTH as a poster presentation with interim findings. The poster's abstract was published in the Journal of Thrombosis and Haemostasis: http://www.professionalabstracts.com/isth2016/programmeisth2016.pdf; DOI: 10.1111/jth.13325. 


\section{Disclosure}

M Wang has served as a consultant to Baxalta, Biogen, CSL Behring, LFB, and Novo Nordisk Inc. K Batt has received grant/research support from Novo Nordisk Inc. and is a scientific advisor for Precision Health Economics. C Kessler has served on advisory boards for Baxalta, Bayer, Biogen, Genentech, Grifols, Novo Nordisk Inc., Octapharma, and Pfizer, and has received grant/research support from Baxter, Bayer, Novo Nordisk Inc., and Octapharma. A Neff has served on advisory boards for Baxalta, Kedrion, and Novo Nordisk Inc. NN Iyer is an employee of Novo Nordisk Inc. DL Cooper is an employee of Novo Nordisk Inc. CL Kempton has served as a consultant to Baxalta, Genentech, and Novo Nordisk Inc. and has received grant/research support from Novo Nordisk Inc. The authors report no other conflicts of interest in this work.

\section{References}

1. Witkop M, Buckner TW, Recht M, et al. Assessments of pain in US adults with hemophilia across patient-reported outcomes in the pain, functional impairment, and quality of life (P-FiQ) study. Haemophilia. 2016; 22(Suppl 4):94.

2. Kempton CL, Recht M, Neff A, et al. Impact of pain and functional impairment in US adult people with hemophilia (PWH): patient-reported outcomes and musculoskeletal evaluation in the pain, functional impairment, and quality of life (P-FiQ) study. Blood. 2015;126(23):39.

3. Witkop M, Neff A, Buckner TW, et al. Self-reported prevalence, description and management of pain in adults with haemophilia: methods, demographics and results from the Pain, Functional Impairment, and Quality of life (P-FiQ) study. Haemophilia. 2017;23(4):556-565.

4. Witkop M, Lambing A, Divine G, Kachalsky E, Rushlow D, Dinnen J. A national study of pain in the bleeding disorders community: a description of haemophilia pain. Haemophilia. 2012;18(3):e115-e119.

5. Witkop M, Lambing A, Kachalsky E, Divine G, Rushlow D, Dinnen J. Assessment of acute and persistent pain management in patients with haemophilia. Haemophilia. 2011;17(4):612-619.

6. Forsyth AL, Witkop M, Lambing A, et al. Associations of quality of life, pain, and self-reported arthritis with age, employment, bleed rate, and utilization of hemophilia treatment center and health care provider services: results in adults with hemophilia in the HERO study. Patient Prefer Adherence. 2015;9:1549-1560.

7. Neufeld EJ, Recht M, Sabio H, et al. Effect of acute bleeding on daily quality of life assessments in patients with congenital hemophilia with inhibitors and their families: observations from the dosing observational study in hemophilia. Value Health. 2012;15(6):916-925.

8. Baumgardner J, Elon L, Antun A, et al. Physical activity and functional abilities in adult males with haemophilia: a cross-sectional survey from a single US haemophilia treatment centre. Haemophilia. 2013;19(4): 551-557.
9. Herdman M, Gudex C, Lloyd A, et al. Development and preliminary testing of the new five-level version of EQ-5D (EQ-5D-5L). Qual Life Res. 2011;20(10):1727-1736.

10. Feldman BM, Funk SM, Bergstrom BM, et al. Validation of a new pediatric joint scoring system from the International Hemophilia Prophylaxis Study Group: validity of the hemophilia joint health score. Arthritis Care Res (Hoboken). 2011;63(2):223-230.

11. Hilliard P, Funk S, Zourikian N, et al. Hemophilia joint health score reliability study. Haemophilia. 2006;12(5):518-525.

12. Shapiro A, Cooper DL. U.S. survey of surgical capabilities and experience with surgical procedures in patients with congenital haemophilia with inhibitors. Haemophilia. 2012;18(3):400-405.

13. Holstein K, Klamroth R, Richards M, Carvalho M, Pérez-Garrido R, Gringeri A; European Haemophilia Therapy Standardization Board. Pain management in patients with haemophilia: a European survey. Haemophilia. 2012;18(5):743-752.

14. Batt K, Recht M, Cooper DL, Iyer NN, Kempton CL. Construct validity of patient-reported outcome instruments in US adults with hemophilia: results from the Pain, Functional Impairment, and Quality of life (P-FiQ) study. Patient Prefer Adherence. 2017;11:1369-1380.

15. Kempton CL, Wang M, Recht M, et al. Reliability of patient-reported outcome instruments in US adult people with hemophilia (PWH): the Pain, Functional Impairment and Quality of life (P-FiQ) study. Patient Prefer Adherence. In press 2017.

16. EuroQoL EQ-5D-5L Index Value Calculator. Available from: http:// euroqol.org. Accessed September 18, 2017.

17. Cleeland C. The Brief Pain Inventory. User Guide. Houston, TX: MD Anderson Cancer Center; 2009.

18. Craig CL, Marshall AL, Sjostrom M, et al. International physical activity questionnaire: 12-country reliability and validity. Med Sci Sports Exerc. 2003;35(8):1381-1395.

19. Maruish ME. User's Manual for the SF-36v2 Health Survey. 3rd ed. Lincoln, RI: Quality Metric Inc; 2011.

20. van Genderen FR, van Meeteren NL, van der Bom JG, et al. Functional consequences of haemophilia in adults: the development of the Haemophilia Activities List. Haemophilia. 2004;10(5):565-571.

21. van Genderen FR, Westers P, Heijnen L, et al. Measuring patients' perceptions on their functional abilities: validation of the Haemophilia Activities List. Haemophilia. 2006;12(1):36-46.

22. Nunnally J. Psychometric theory. New York, NY: McGraw-Hill; 1978 .

23. Kline P. Computing test-reliability. A Handbook of Test Construction: Introduction to Psychometric Design. New York, NY: Methuen \& Co; 1986:118-132.

24. Goto M, Takedani H, Yokota K, Haga N. Strategies to encourage physical activity in patients with hemophilia to improve quality of life. J Blood Med. 2016;7:85-98.

25. Orejuela Upegui A, Humberto Ramirez J, Restrepo Avenia JM, Fandino-Losada A. Validation of the HAL questionnaire (Haemophilia Activities List) about perception of functionality in adults of a Program in Cali in 2014. WFH 14th International Musculoskeletal Congress. 2015:MP-106.

26. Centers for Disease Control and Prevention. Report on the Universal Data Collection Program, 2005-2009, January 2014:1-26. 


\section{Supplementary material}

List of independent ethics committees/institutional review boards

1. Munson Medical Center, 1105 Sixth Street, Traverse City, MI 49684-2386, USA

2. Emory University, 1599 Clifton Road, 5th Floor, Atlanta, GA 30322, USA

3. St Vincent Hospital and Health Care Center, Inc., 8402 Harcourt Road, Suite 805, Indianapolis, IN 46260, USA

4. Western Institutional Review Board, 3535 7th Avenue SW, Olympia, WA 98502-5010, USA

5. Henry Ford Health System, CFP-Basement 046, 2799 West Grand Boulevard, Detroit, Ml 48202-2689, USA, Chairperson: Dr Timothy Roehrs, PhD

6. Vanderbilt University, 504 Oxford House, Nashville, TN 37232-4315, USA

7. Western Institutional Review Board, 1019 39th Avenue SE, Puyallup, WA 98374, USA
8. University of Colorado Multiple, Institutional Review Board, 13001 E. 17th Place, Building 500, Room N3214, Aurora, CO 80045, USA

9. Michigan State University, Olds Hall, 408 West Circle Drive, \#207, East Lansing, MI 48824, USA, Chairperson: Dr Ashir Kumar

10. Oregon Health \& Science University, 3181 SW Sam Jackson Park Road, Portland, OR 97239-3098, USA

11. University of Minnesota, D528 Mayo Memorial Building, 420 Delaware Street S.E., MMC 820, Minneapolis, MN 55455, USA

12. Rush University Medical Center, 1653 West Congress Parkway, Chicago, IL 60612-3833, USA

13. Wake Forest University Health Services, Medical Center Boulevard, Winston-Salem, NC 27157-1023, USA

14. Georgetown University, 37th and O Streets, N.W., Washington, DC 20057, USA

\section{Publish your work in this journal}

Patient Preference and Adherence is an international, peer-reviewed, open access journal that focuses on the growing importance of patient preference and adherence throughout the therapeutic continuum. Patient satisfaction, acceptability, quality of life, compliance, persistence and their role in developing new therapeutic modalities and compounds to optimize clinical outcomes for existing disease states are major areas of interest for the journal. This journal has been accepted for indexing on PubMed Central The manuscript management system is completely online and includes a very quick and fair peer-review system, which is all easy to use. Visit http://www. dovepress.com/testimonials.php to read real quotes from published authors. 